\title{
PERSPECTIVAS \\ DE UMA FUNDAMENTAÇÃO \\ PRAGMÁTICO-LINGÜÍSTICA
}

\author{
Vânia Dutra de Azeredo*
}

RESUMO - Este artigo analisa a distinção entre dois tipos de fundamentação, a lógico-semântica e a pragmático-lingüística, a partir da perspectiva habermasiana. Esta última apresenta, para a justificação das normas morais, uma ética do discurso. Operando ainda em outro registro, procura-se mostrar que o esquema habermasiano, inicialmente voltado para a moral, pode aplicar-se à política, quando as proposições políticas são tratadas de modo análogo às morais. Nesse caso, utilizam-se os conceitos habermasianos como operadores.

PALAVRAS-CHAVE - Ética. Política. Atos de fala. Atitude performativa. Agir comunicativo. Discurso.
ABSTRACT - This article offers an analysis of the distinction between two types of argumentation, namely the logic-semantic and the so-called pragmatic-linguistic approach. The last one presents, for the justification of moral norms, an ethics of discourse. Dealing with another aspect as well, it attempts to show that Habermas's scheme, initially devoted to moral thought, may be applied to politics, whenever political propositions are treated analogously to moral ones. In that case, concepts of Habermas's theory are used merely as operators.

KEY WORDS - Ethics. Politics. Speech acts. Performative attitude. Communicative action. Speech.

Em que medida se pode afirmar que dever fazer algo implica, ao mesmo tempo, poder apresentar razões acerca dessas realizações no sentido de justificações plausíveis para a escolha feita, ou, talvez, para aquilo que, em tese, deveria ser. No domínio do agir, especialmente, há controvérsias marcantes que separam diametralmente as perspectivas que compreendem o agir a partir de atitudes emocionais "cegas", recusando, por conseguinte, qualquer tipo de justificação racional para as normas morais, de uma construção explicativa que se proponha fundamentar as questões práticas, isto é, reivindicar para as normas morais um estatuto similar ao das proposições descritivas, afirmando serem passíveis de validação. É, de fato, um embate acirrado acerca do agir orientado para fins em termos de uma posição cognitivista ou não-cognitivista que o explique. Não se trata de buscar máximas que vigorem incondicionalmente, mas de pensar em uma conciliação viável entre a postulação de máximas e a sua correspondente justificação.

* Professora do Departamento de Filosofia e Psicologia da UNIJUí.

\begin{tabular}{|l|l|l|l|l|l|}
\hline VERITAS & Porto Alegre & v. 51 & n. 1 & Março 2006 & p. 112-120 \\
\hline
\end{tabular}


Ora, as questões referentes, por exemplo, ao que é bom ou ao que é justo são, indiscutivelmente, prementes para a existência humana. Uma escolha nesse nível tem reflexos marcantes na comunidade em que se realiza, haja vista a extensão aplicativa das normas/imperativos que visam a regulamentar as relações entre os homens em uma determinada sociedade. É preciso, entretanto, separar o domínio concreto do reflexivo, pois, ainda que no cotidiano as pessoas ajam de acordo com uma compreensão do que é bom ou do que é justo, a problematicidade reside em explicar essa compreensão e, nesse sentido, tem-se de admitir que as proposições "O livro é pesado" e "Paulo é bom" são diferentes. Não se trata de uma diferença lógica em termos de forma, pois ambas são redutíveis à fórmula "s é p"; todavia, para além dessa formalização, há um significado e uma função diversos que, em princípio, permitem verificar empiricamente a primeira proposição e não o permitem com relação à segunda, inviabilizando, segundo alguns estudiosos, sua justificação. As proposições normativas não podem ser verificadas empiricamente, pois a alusão é feita, via de regra, ou àquilo que deve ser - não há fato ou situação possível que sirva de referencial para a sua demonstração - ou a juízos de valor acerca do que é bom ou justo, o que requer uma prévia determinação de tais juízos. Há, assim, uma impossibilidade de atribuir a essas proposições um valor de verdade, requerendo, em uma perspectiva lógico-semântica, destituí-las de significado. ${ }^{1}$

No mesmo horizonte temático - possibilidade ou não de justificação - em que se situam as questões referentes às decisões práticas, situam-se as concernentes às decisões políticas que, envolvendo uma adesão do sujeito, se aproximam de uma perspectiva moral. Se tais pretensões são excluídas do âmbito da ética, o são igualmente do âmbito da política, pois poder-se-ia determinar, em termos fatuais, o que se processa em uma dada sociedade, ainda assim não se poderia discorrer, com base em razões, sobre aquilo que deveria ser, sem que se caia no mesmo problema da justificação ética. Ou se recorre a um ideal de relações sociais, de representantes etc., que tem por base um fundamento absoluto, cuja recusa em termos de sustentação é imediata, ou, em se recusando este, parte-se de adesões legitimadoras que não encontram um ponto de apoio epistêmico que corrobore tal atitude, já que não existem condições empíricas de sua verificação. Assim, esse tipo de proposição com tal conteúdo político seria, igualmente, desprovido de sentido em um quadro lógico-semântico.

1 Trata-se da tradição analítica ligada ao Círculo de Viena, que considera como tendo sentido apenas as proposições às quais se pode atribuir um valor de verdade, e cuja verificação requer que o seu significado possa ser reduzido a um conjunto de dados empíricos. A ocorrência desses dados ou não é que determina a verdade ou falsidade da referida proposição, sendo a possibilidade de tal atribuição condição de significado. R. Carnap, em "Pseudoproblemas na filosofia", afirma: "Somente os enunciados que possuem conteúdo fatual são teoricamente significativos; enunciados (ostensivos) que não podem, em princípio, estar fundamentados pela experiência são carentes de significado" (Carnap 3, p. 168). A filiação ou não a essa tradição tem reflexos marcantes sobre a possibilidade de justificar as normas morais. Para os que compartem tal fundamentação, não é possível conferir a essas proposições qualquer função cognitiva, não havendo, assim, possibilidade de sua justificação ou fundamentação racional. 
Conquanto tal destituição seja possível, seguindo um dado modelo explicativo, não o é se a pressuposição for outra, haja vista as tentativas recorrentes de sustentar, com base em razões, as normas morais. Nesse sentido, encontra-se a tentativa de elaborar uma ética cognitivista, formalista e universalista empreendida por Habermas, que tem, necessariamente, de se situar em outro patamar, implicando compreender a linguagem de um modo diverso; isso pode ser observado, quando o autor diferencia "dizer algo acerca do mundo" de "dizer algo para alguém", tentando apresentar duas atitudes, sejam elas, a objetivante, "quem observa ou opina que 'p' ou quem tem a intenção de 'p'”, e a performativa, "Quem participa dos processos de comunicação ao dizer algo e ao compreender o que é dito" (Habermas, 1989, p. 42). Mas a cisão radical entre uma e outra atitude aparece mais por parte da primeira, visto que a atitude performativa possibilita a passagem entre as três pessoas do processo comunicativo em vista de situar-se nesse processo: "quem participa do processo de comunicação ao dizer algo e ao compreender o que é dito - quer se trate de uma opinião que é relatada, uma constatação que é feita, de uma promessa ou de uma ordem que é dada; quer se trate de intenções, desejos, sentimentos ou estados de ânimo que são expressos -, tem sempre de assumir uma atitude performativa" (id., ibidem), escreve em Consciência moral e agir comunicativo. Somente a atitude performativa, segundo Habermas, permite, de um lado, a mudança entre uma e outra pessoa - objetivante, conforme a regras ou expressiva - e, de outro, possibilita a validação. Essa atitude encerraria uma pretensão de validez que se estende aos domínios daquilo que é dito acerca do mundo, assim como das normas postuladas e dos comportamentos manifestos. Ela permite, acrescenta o filósofo, "uma orientação mútua por pretensões de validade (verdade, correção normativa, sinceridade) que o falante ergue na expectativa de uma tomada de posição por sim/não da parte do ouvinte" (id., ibidem).

O que nos parece decisivo, nesse recurso habermasiano à atitude performativa, é que, mediante tal procedimento, se torna possível ao autor resgatar a função da linguagem de coordenar e integrar os projetos de diferentes atores. A linguagem desempenharia, assim, a função de integração social, que será, justamente, o pano de fundo de sua teoria do agir comunicativo². Além disso, Habermas preci-

2 Habermas, no texto "Ciências sociais reconstrutivas versus ciências sociais compreensivas", busca distinguir a epistemologia, que trata apenas da relação entre linguagem e realidade, da hermenêutica, que se ocupa das relações estabelecidas a partir de um proferimento. Tais especificações, para além de diferirem um e outro modo de abordagem, permitem ao autor, seguindo a linha hermenêutica, tomar a linguagem em ação e, assim, remetê-la a "tríplice relação de um proferimento que serve (a) como expressão da intenção de um falante, (b) como expressão para o estabelecimento de uma relação interpessoal entre falante e ouvinte e (c) como expressão sobre algo no mundo", sob duplo aspecto. A mesma conexão pode ser referida à perspectiva do falante e do ouvinte, mas também ser vista a partir de uma conexão no mundo da vida que expressará as três funções preenchidas pela linguagem: “a) função da reprodução cultural ou da presentificação das tradições, b) a função de integração social ou da coordenação dos planos de diferentes atores na integração social, e c) a função da socialização da interpretação cultural das necessidades". É a partir da terceira função da linguagem que o filósofo alemão desenvolve sua teoria do agir comunicativo (Habermas 4, 41 - 2). 
sou distanciar-se de uma fundamentação lógico-semântica e filiar-se a uma fundamentação pragmático-lingüística, já que, no domínio da argumentação discursiva, visa a encontrar elementos que lhe possibilitem validar as normas morais e, com isso, conferir ao agir o estatuto de empreendimento racional. Procura, desse modo, rejeitar a tese de que as ações orientadas para fins são produto de uma decisão cega; recusa a afirmação de que "questões moral-práticas do tipo: 'O que devo fazer?' são afastadas da discussão racional, na medida em que não podem ser respondidas do ponto de vista da racionalidade meio-fim" (id., ibidem, p. 63). No limite, está a recusa em definir a razão como eminentemente calculadora, restringindo suas avaliações a verdades de fato ou a relações matemáticas.

Supondo-se que o empreendimento habermasiano obtenha êxito, pode-se, de uma forma análoga, pensar em validar proposições de conteúdo político, a partir de uma fundamentação discursiva, já que, nesse caso, a referência não seria o fato existente, mas os pressupostos que viabilizariam os discursos políticos. Poderse-ia, por exemplo, argumentar, no plano de tal discurso, acerca da legitimidade ou não de um representante, sem que se caia no abismo, semanticamente postulado, de derivar de um fato existente a justificação de algo não-existente. Nesse caso, pode-se admitir que, através de argumentos, seria viável apresentar razões que sustentem a possibilidade de um discurso acerca daquilo que "deveria ser" no âmbito da política a partir de uma teoria especial da argumentação.

Na visão de Habermas, é possível à ética filosófica "assumir sem mais a figura de uma teoria especial da argumentação" (id., ibidem), bem como refutar as pressuposições dos não-cognitivistas, através de dois procedimentos, quais sejam, introduzir um princípio que permita um consenso em argumentos morais e recusar a tese de que somente no âmbito da compreensão de verdade proposicional poderiam ser validadas ou não as proposições normativas. ${ }^{3}$ Não se trata de reduzir as

3 Habermas, em "Teorias da verdade", recusa as condições de verdade lógico-semântica e propõe uma teoria geral da verdade que seria consensual, isto é, o consenso entre aqueles que argumentam é posto como critério de verdade, uma vez que as regras adotadas são pragmáticas, regras da linguagem que fazem parte da comunicação, e não regras semânticas, que visam a determinar o significado. Convém observar que a teoria consensual da verdade recebeu algumas críticas, em especial, por E. Tugendhat. Consoante o filósofo, "a objeção mais imediata contra uma teoria consensual da verdade consiste no fato de que um consenso qualquer não pode ser considerado como critério de verdade, mas somente um consenso qualificado" (Cf. E. Tugendhat 8). Habermas, em "Notas pragmáticas para a fundamentação de uma ética do discurso", continua a rejeitar uma compreensão de verdade proposicional e pressupõe, sempre, uma compreensão de verdade pragmática. Nesse ponto, inclusive, acreditamos que ele se filia a Austin com relação a mudança de paradigma na filosofia analítica. Austin considera a linguagem como ação, recusando a tônica do significado e propondo o conceito de eficácia do ato lingüístico. Esse ato será feliz ou infeliz conforme suas condições de sucesso na interação comunicativa. Com a proposição de que as condições de uso determinam o significado, a própria noção de significado perde sua carga semântica, pois a linguagem passa a envolver os elementos do contexto de enunciação, assim como as convenções e intenções do falante. Austin substitui a teoria do significado por uma teoria da ação, pois o dizer algo implica realizar algo mediante a linguagem. Daí a linguagem ser considerada enquanto ação e a verdade ser situada em uma dimensão pragmática, contexto de enunciação, e não semântica. Em Quando dizer é fazer, caracteriza o proferimento performativo como "aquela expressão lingüística que não consiste, ou não consiste, apenas, em dizer algo, mas em fazer algo, não sendo um relato, verdadeiro ou falso sobre alguma coisa" (Austin 2, p. 38). Austin trabalha com as forças dos profe- 
proposições normativas às descritivas, mas, visando a explicar o sentido da "correção normativa", pensar em uma pretensão de validez análoga à verdade.

Na ótica habermasiana, os dilemas morais surgem primeiramente no mundo da vida - o Lebenswelt é o lugar da moral para o filósofo -, e é já nesse mundo que ele identifica pretensões de validade erguidas pelos atores em seus atos de fala. Ele denomina de comunicativas as "interações nas quais as pessoas envolvidas se põem de acordo para coordenar seus planos de ação, o acordo alcançado em cada caso medindo-se pelo reconhecimento intersubjetivo das pretensões de validez" (id., ibidem, p. 79). O agir comunicativo se processa no mundo da vida, e nele deverão estar as pretensões que viabilizam situar a correção normativa no plano da argumentação. Os atores, ao realizarem um ato de fala, erguem sempre ou pretensões de verdade, quando se trata da referência a um estado de coisas, ou pretensões de correção, enquanto dirigida às relações interpessoais reguladas, ou, ainda, pretensões de sinceridade, quando pertencem ao mundo subjetivo de cada um. As pretensões de validade, reconhecidas intersubjetivamente, são o pano de fundo dos consensos atingidos, por isso têm de perpassar o mundo das coisas existentes, das relações sociais e das vivências.

No agir comunicativo, os falantes motivam-se racionalmente a um ato de adesão, que Habermas estabelece mediante o recurso ao efeito ilocucionário que os atos de fala teriam. "Enquanto no agir estratégico um atua sobre o outro para ensejar a continuação desejada de uma interação, no agir comunicativo um é motivado racionalmente pelo outro por uma ação de adesão - e isso em virtude do efeito ilocucionário de comprometimento que a oferta de um ato de fala suscita" (id., ibidem), diz em Consciência moral e agir comunicativo. Pressupõe, assim, a realização de algo ao dizer. Haveria um comprometimento exigido por esse dizer que é, ao mesmo tempo, uma ação; em vista disso, as relações sociais têm a forma de ações comunicativas, cuja coordenação se efetiva devido à dupla estrutura da comunicação lingüística.

A linguagem não contém apenas um conjunto de sentenças com um determinado conteúdo, mas contém, também, os condicionantes para a sua aplicação, tendo em vista que a mesma sentença pode ter um sentido pragmático, alusivo ao contexto de enunciação, diferente conforme seja proferida como ordem, promessa ou afirmação. Tal sentença, inclusive, tem uma parte proposicional e uma parte

rimentos, diferindo, em vista disso, o ato de dizer algo, ato de falar, que denomina de locucionário; o ato feito ao dizer, intenção da fala, que seria o ilocucionário e o ato obtido porque se disse algo, sentido da fala, que corresponde ao perlocucionário. No mesmo texto, afirma: "Expliquei a realização de um ato nesse novo sentido como sendo a realização de um ato ilocucionário, isto é, a realização de um ato ao dizer algo em oposição à realização de um ato de dizer algo. Vou referir-me à doutrina dos diferentes tipos de funções da linguagem que aqui nos interessam como sendo a doutrina das forças 'ilocucionárias'” (id., ibidem, p. 89). O autor reconhece que toda proposição, proferida em uma dada situação lingüística, deve ser analisada sob a ótica das forças pragmáticolingüísticas que ela encerra. A teoria dos atos de fala de Austin suscita diversas questões atinentes à linguagem, contudo, interessa aqui resgatar os elementos presentes na ética do discurso proposta por Habermas. Sem dúvida, os performativos, assim como, de um modo geral, as forças dos atos lingüísticos, propostas por Austin, estão presentes na construção teórica habermasiana e são, inclusive, condição de possibilidade para um agir comunicativo. 
performativa, já que, ao ser proferida, ao mesmo tempo, designa algo e realiza uma ação - o exemplo recorrente é: "Eu prometo que p". A parte performativa compreende a ação feita, e a parte proposicional aquilo que está sendo designado pela proposição, no caso p. ${ }^{4}$ As ações lingüísticas passam a ser ações comunicativas, porque os atos lingüísticos são, de fato, atos.

Os falantes erguem pretensões de validade que podem ser resgatadas, gerando, por conseguinte, a motivação racional de aceitação do ouvinte. No caso da verdade e correção, ele a resgatará discursivamente e, no caso das pretensões de sinceridade, pela constância de um determinado comportamento. Instaurando-se a confiança, vigoram, segundo Habermas, "aquelas obrigações relevantes para a seqüência da interação que estão contidas no significado do que foi dito. Assim, por exemplo, no caso das ordens e instruções, as obrigações de agir valem, em primeira linha, para o destinatário; no caso de promessas e declarações, para o falante; no caso de acordos e contratos, simetricamente para os dois lados; no caso das recomendações e advertências com teor normativo, assimetricamente para os dois lados" (id., ibidem). É a possibilidade latente de apresentar razões para as ações feitas que permite a coordenação entre os atores, pois a possibilidade de recorrer a argumentos que justifiquem a pretensão viabiliza a coordenação, embora existam diferenças entre uma e outra forma de validação.

Há uma diferença importante, no que tange à relação entre as normas e os atos de fala e entre esses e as proposições referentes aos estados de coisas, que se torna fundamental para a determinação das condições de validade. A validez normativa apresenta a seguinte peculiaridade, consoante Habermas: "As pretensões normativas têm sua sede primeiramente em normas e só de maneira derivada em atos de fala" (id., ibidem, p. 81), uma vez que a norma reivindica, por si mesma, a validez. É o caso, citado pelo autor, da proposição "Não se deve matar ninguém”, que aparece enquanto expressão impessoal para a própria norma. Os atos de fala referem-se a ela de modo secundário. Isso não se processa com as proposições descritivas, já que, nesse caso, os atos de fala aparecem como sede das pretensões de verdade. Dizer algo acerca do mundo objetivo das coisas existentes não implica uma validez independente do dizer referido a um estado de coisas; o que determina, na ótica habermasiana, uma assimetria entre condições de validade remetidas às pretensões de validez normativa ou de verdade.

A realidade social, à qual nos referimos com atos de fala regulativos, já está desde o início numa relação interna com pretensões de validade normativas. Ao contrário, as pretensões de verdade não são de modo algum inerentes às entidades elas próprias, mas apenas aos atos de fala com que nos referimos às entidades do discurso constatativo de fatos, a fim de representar estados de coisas (id., ibidem, 81-2).

4 Nos textos de Austin encontramos vários exemplos performativos. Julgamos interessante citar os seguintes: “'Aceito, esta mulher como minha legítima esposa', 'Batizo este navio com o nome de Rainha Elizabeth', Lego a meu irmão este relógio'”. O autor introduziu esta denominação, recorrendo ao "verbo inglês to perform, verbo correlato do substantivo 'ação', e indica que, ao se emitir o proferimento, está se realizando uma ação, não sendo, conseqüentemente, considerado um mero equivalente a dizer algo" (ibidem, p. 23-8). 
A diversidade subjacente às respectivas pretensões determina modos diferentes de aceder à justificação. Habermas remete a fundamentação ética ao âmbito dos discursos práticos, já que pressupõem um vínculo necessário entre a linguagem e o mundo social expresso pela peculiar relação existente entre as pretensões de validez presentes nas normas e as erguidas com atos de fala regulativos. Esse vínculo não é estabelecido entre a linguagem e o mundo objetivo, pois, nesse caso, não há ambigüidade entre os enunciados verdadeiros e os estados de coisas. Com relação às normas, "a existência ou validez social das normas não quer dizer nada ainda acerca da questão se estas também são válidas" (id., ibidem, p. 82), afirma Habermas. Requer-se, por conseguinte, tanto a aceitação da validez social quanto a possibilidade de resgatar tal pretensão com razões - isso, inclusive, sustenta a aceitação social das normas. Mas, nesse caso, há, para o filósofo alemão, uma conexão entre "a existência de normas de ação" e "a esperada possibilidade de fundamentação das correspondentes proposições deônticas" (cf. Habermas 4, p. 83). No limite, é essa conexão que remete a justificação das normas morais a uma lógica dos Discursos práticos.

A impossibilidade de elaborar condicionantes epistemológicos que, em um primeiro momento, assegurem a validade dos juízos morais remete a sua problematização, incontinente, à esfera argumentativa, exigindo que se estabeleça o que Habermas denomina de princípio-ponte, que asseguraria a passagem do particular ao universal, no âmbito da argumentação prática. Os discursos teóricos têm um princípio similar que é, para o filósofo, a indução. O princípio de Universalização deveria desempenhar "um papel equivalente ao princípio da indução no Discurso da ciência empírica" (Habermas 4, p. 84), promovendo, nos discursos práticos, o assentimento irrestrito de todos os envolvidos e conferindo às normas morais o estatuto de impessoalidade ou universalidade. "O princípio-ponte possibilitador do consenso deve, portanto, assegurar que somente sejam aceitas como válidas normas que exprimem uma vontade universal; é preciso que elas se prestem, para usar uma fórmula que Kant repete sempre, a uma "lei universal" (id., ibidem), escreve em Consciência moral e agir comunicativo.

A filiação de Habermas aos pressupostos kantianos é manifestamente expressa, já que o autor situa seu discurso no horizonte de uma razão que justifique a ética. Nada obstante, a busca de um consenso, que perpassa a elaboração de sua teoria, situa a fundamentação no plano dialogal, pois pressupõe que as decisões, com base em razões, são produto de uma argumentação. Deve haver, assim, o reconhecimento, por parte de todos os concernidos, levando-os a recusar a perspectiva de uma esfera monológica de decisões e a postular uma esfera dialogal enquanto seu plano legítimo; em vista disso, a universalização dos interesses universalizáveis. A afirmação pareceria redundante, todavia ele pressupõe o assentimento de todos os envolvidos enquanto condicionante de uma universalização. Ora, nesse ponto, especialmente, podemos resgatar as pretensões de justificação no âmbito político, pois, nesse caso, aquilo que deveria ser atingido, em termos de relações entre os grupos ou da legitimidade de um representante, poderia ser produto de um discurso. Os mesmos pressupostos necessários da argumentação utilizados por Habermas para 
fundamentar a ética poderiam aplicar-se à política, já que as decisões, em tese, são produto de um consenso que implica, necessariamente, o assentimento de todos. Não se trata, nesse caso, de interesses particulares, mas de interesses universalizáveis que podem ser assegurados, mediante a introdução de um princípio de Universalização:

(U) Toda norma válida tem de preencher a condição de que as conseqüências e efeitos colaterais que previsivelmente resultem de sua observância Universal, para a satisfação dos interesses de todo indivíduo, possam ser aceitas sem coação por todos os concernidos (id., ibidem, p. 184).

Trata-se, para Habermas, de um princípio que, enquanto regra de argumentação, assegura a validação das normas enquanto produto consensual de um discurso prático. As normas morais, que no mundo da vida se tornam problemáticas, podem ser validadas em discursos práticos, desde que se possa garantir o assentimento de todos os concernidos mediante a introdução de U, já que o próprio assentimento de todos é condição para que as normas possam ser validadas. Esse princípio funcionaria, por não se ter efetivado, na maior parte dos discursos práticos, como uma espécie de ideal regulador que garantiria o sucesso dos discursos práticos, apesar de não ser propriamente, para o autor, um ideal, já que é uma condição real dos próprios discursos, sem a qual não haveria participação nos argumentos morais: "Introduzi (U) como uma regra de argumentação que possibilita o acordo em Discursos práticos sempre que as matérias possam ser regradas no interesse igual de todos os concernidos" (id., ibidem, p. 87), diz o filósofo.

A fundamentação de tal princípio é a questão-chave da proposição de uma ética do Discurso, visto ela sustentar a validação das normas com base em razões. Nessa perspectiva, o princípio U é fundamentado a partir de conjecturas argumentativas, pois, para Habermas, existem pressupostos necessários da argumentação que não podem ser recusados. ${ }^{5}$ No domínio discursivo, não se podem negar os pressupostos de uma argumentação sem, ao mesmo tempo, inserir-se nessa argumentação, reconhecendo, em certa medida, tais pressupostos. Ora, a recusa aparece como um argumento a favor de sua necessidade, pois o falante, ao introduzir um argumento contrário à possibilidade de fundamentação, recorre aos mesmos pressupostos que tenta negar, terminando, assim, por demonstrá-los mediante a contradição

5 Os pressupostos necessários da argumentação Habermas mostra, mediante o recurso à noção de contradição performativa desenvolvida, nesse plano, por K. Apel. Tem-se uma contradição performativa sempre que houver uma dissonância entre o conteúdo proposicional e o enunciado proferido, em se tratando do mesmo sujeito 'eu'. Habermas recorre ao exemplo de Apel: Para o enunciado: (1) Eu não existo (aqui e agora) o falante ergue uma pretensão de verdade; ao mesmo tempo, ao proferi-la, ele faz uma inevitável pressuposição de existência cujo conteúdo proposicional pode ser expresso pelo enunciado: (2) Eu existo (aqui e agora) (sendo que em ambas as proposiç̃es o pronome pessoal se refere à mesma pessoa). Ora, para os respectivos autores um falante que queira rejeitar as pressuposições necessárias da argumentação, precisa pressupô-las para fazê-lo caindo em uma contradição performativa. Em vista disso, de um lado, a impossibilidade de recusar esses pressupostos, e, de outro, a fundamentação conseqüente de U a partir deles. Vale acrescentar que Habermas comparte com Apel a argumentação referente à contradição performativa rejeitando, entretanto, a pretensão de chegar a uma fundamentação última (cf. Habermas 4, p. 119-31). 
performativa em que incorre. "Na fundamentação de 'U', trata-se especialmente da identificação de pressupostos pragmáticos, sem os quais o jogo da argumentação não funciona; qualquer um que participe de uma prática argumentativa já deve ter aceito essas condições de conteúdo normativo. Pelo simples fato de terem passado a argumentar, os participantes estão necessitados a reconhecer esse fato" (id., ibidem, p. 161). Não há, entretanto, a intenção de, mediante tal princípio, obter uma fundamentação última, visto que, para o filósofo, a ética do Discurso "vai inserir-se no círculo das ciências sociais reconstrutivas que tem a ver com os fundamentos racionais do conhecer, do falar e do agir" (id., ibidem, p. 121). No limite, situar-se em uma ética do Discurso requer o retorno aos diferentes modos de uso da linguagem, privilegiando a instância compreensiva: "Ou bem a gente diz o que é o caso ou o que não é o caso ou bem a gente diz algo para outrem, de tal modo que ele compreenda o que é dito" (id., ibidem, p. 40).

Ora, uma vez que se situa a justificação de proposições normativas em uma fundamentação pargmático-lingüística e se introduz ' $U$ ' como uma regra de argumentação que visa a assegurar a participação de todos os concernidos em uma argumentação e, inclusive, suprime-se qualquer possibilidade de coação na aceitação de suas consequiências, atinge-se uma posição privilegiada para discorrer sobre aquilo que 'deve ser' com base em razões. Nesse caso, 'o dever-ser' não deriva de uma subjetividade isolada, mas de uma interação possível intersubjetivamente. Todos os envolvidos, com as mesmas condições de participarem de argumentações, validam as normas e atingem um consenso. Se a aplicação desses pressupostos viabiliza justificar normas morais, pode, igualmente, justificar as pretensões de legitimidade, em termos políticos, já que 'U', apesar de ser um princípio que visa validar as normas, em termos de justiça, é, primordialmente, uma regra de argumentação fundamentada a partir de pressupostos necessários da argumentação em geral. Se tais pressupostos são aplicáveis à ética, o são igualmente à política, em especial, no que se refere à dimensão que mantém uma grande proximidade com a moral. Não obstante, tal afirmação, assim como a assimilação incontestável ou não das pressuposições habermasianas exigirem discussões ulteriores.

\section{Referências}

APEL, Karl-Otto. Estudos de moral moderna, Trad. de Benno Dischinger. Petrópolis: Vozes, 1994.

AUSTIN, J. L. Quando dizer é fazer. Trad. de Danilo Marcondes de Souza Filho. Porto Alegre: Artes Médicas, 1990.

CARNAP, Rudolf. "Pseudoproblemas na filosofia”, In: Coleção Os pensadores. São Paulo: Abril Cultural, 1980.

HABERMAS, J. Consciência moral e agir comunicativo, Trad. Guido Antônio de Almeida. Rio de Janeiro: Tempo brasileiro, 1989.

"Para o uso pragmático, ético e moral da razão prática". In: Dialética e liberdade. Ernildo Stein e Luís Alberto De Boni (Org.), Porto Alegre: Vozes, 1993, p. 288-304.

Théorie de l'agir communicationel. Trad. Jean-Louis Schlegel, Paris: Fayard, 1987.

ROUANET, Sérgio Paulo, "Ética iluminista e ética discursiva". In: Tempo brasileiro, 1989, p. 23-78.

TUGENDHAT, E. Lições sobre ética, Revisão e organização da tradução Ernildo Stein e Ronai Rocha. Petrópolis: Vozes, 1997. 